\title{
Posterolateral Percutaneous Endoscopic Discectomy with Partial Pediculotomy for the L1-L2 High-Grade Downward Migrated Disc Herniation
}

\author{
Yoshihiro Kitahama ${ }^{1,5 *}$, Hisashi Koga ${ }^{2}$, Kawaoka Taigo ${ }^{3}$, Manabu Minamii, ${ }^{1,4}$, Hideaki Miyake ${ }^{5}$ and Seiji Yamamoto $^{5}$ \\ ${ }^{1}$ Omaezaki Municipal Hospital, Spine Center, Japan
}

${ }^{2}$ Iwai Orthopedic Surgery Hospital, Spine Center, Japan

${ }^{3}$ Kawasaki Hospital, Neurosurgery, Japan

${ }^{4}$ Heisei Memorial Hospital, Spine Disorder Treatment Center, Japan

${ }^{5}$ Hamamatsu University School of Medicine, Cooperative Major of Medical Photonics, Japan

Submission: March 19, 2018; Published: April 11, 2018

*Corresponding author: Yoshihiro Kitahama Omaezaki Municipal Hospital, Spine Center, 2060 Ikeshinden, Omaezaki, Shizuoka 437-1696, Japan, Tel: +81-537-86-8511; Email: ykitah@gmail.com

\begin{abstract}
Background: Percutaneous endoscopic discectomy (PED) is one of the most useful minimally invasive surgical techniques for lumbar disc herniation (LDH). However, high-grade migrated disc is difficult to treat with only the standard posterolateral approach (posterolateral PED, PLPED).

Purpose: To overcome this difficulty, we combined the pediculotomy with PLPED for the treatment of high-grade migrated LDH. The pediculotomy is the recent technic for PED that has been explored with development of high-speed drill.

Case report: A 72-year-old man had a 6-month history of left L2 radiculopathy. His general state was too poor to perform general anesthesia and invasive surgery. The left L1-L2 downward migrated fragment compressed his L2 nerve root axial portion on magnetic resonance imaging. PLPED with partial pediculotomy was used for complete total removal, which cured his symptoms without any complications. Thirty minutes after fragmentectomy, we needed to control 100-ml bleeding from the anterior epidural venous plexus (AEVP).

Discussion: Upper-level migrated large lumbar disc fragments often require facetectomy with some fusion in conventional microscopic surgery. This case was too complicated for indicating the conventional technique. Only the flexible bipolar device helps control hemostasis in the PED system, but some bleeding cannot be controlled easily.

Conclusion: PLPED with partial pediculotomy was useful for a migrated fragment in patients with poor general conditions. Although the PED system requires a new device to control the bleeding from the AEVP.
\end{abstract}

Keywords: Lumbar disc herniation; Posterolateral percutaneous endoscopic discectomy

\section{Introduction}

Percutaneous endoscopic discectomy (PED) is one of the most useful minimally invasive surgery for lumbar disc herniation (LDH) (1,2). Especially, high-grade migrated fragments are difficult to treat with the standard posterolateral PED (PLPED) technique $(3,4)$. PED with a high-speed drill is a minimally invasive method of approaching the deep narrow lumbar space (5-8). This paper presents a successful case of PLPED with partial pediculotomy for a high-grade downward migrated fragment and discusses a hemostatic technique for severe bleeding.

\section{Case Report}

A 72-year-old man had severe untreatable lumbago and left femoral radicular pain for 6 months. His health condition was poor with chronic renal failure requiring dialysis 3 times per week, hypertrophic cardiomyopathy, and obstructive ventilation impairment .The initial physician referred the patient to us to undergo a minimally invasive spine surgery.

During his first visit, the patient's numeric rating scale (NRS) scores were 8/10 for low back pain and 8/10 for left front femoral pain. His leg pain increased after 10 minutes of slow walking, so he needed a wheelchair. Neurological examination revealed normal deep tendon reflexes. His thigh circumference was asymmetrical (right, $35.5 \mathrm{~cm}$; left, $35.0 \mathrm{~cm}$ ). Owing to his pain, he could not get into a prone position for examination with the femoral nerve stretch test. The straight leg raising test result was negative bilaterally. 
On sagittal T2-weighted magnetic resonance imaging (MRI),a high-grade downward migrated disc was observed at the L1-L2 level on the left side (Figure 1a). The axial view at the L2 pedicle midline level showed a large fragment impinging the L2 nerve root (Figure 1b).

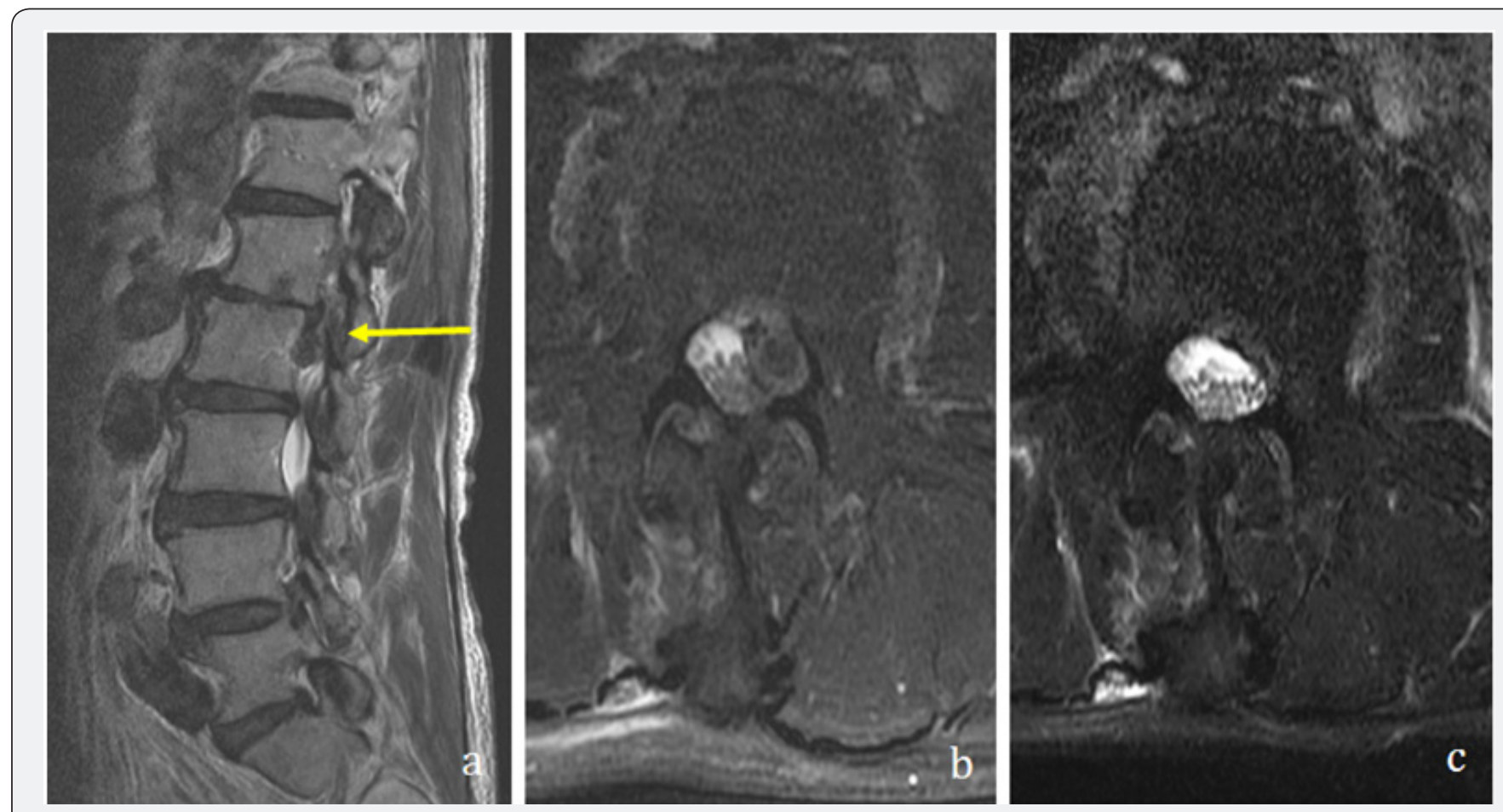

Figure 1: Magnetic resonance imaging (MRI) scans before and after posterolateral percutaneous endoscopic discectomy (PLPED).

a: Left para-sagittal MRI scan before PLPED. The herniated fragment migrated over the L2 vertebral body at the midline level.

b: Axial view of a MRI scan through the L2 pedicle level before PLPED. A large fragment impinged the left L2 nerve root.

c: Axial view of a MRI scan through the L2 pedicle level after PLPED. Note the total removal of the migrated fragment and decompression of the left L2 nerve root and cauda equina.

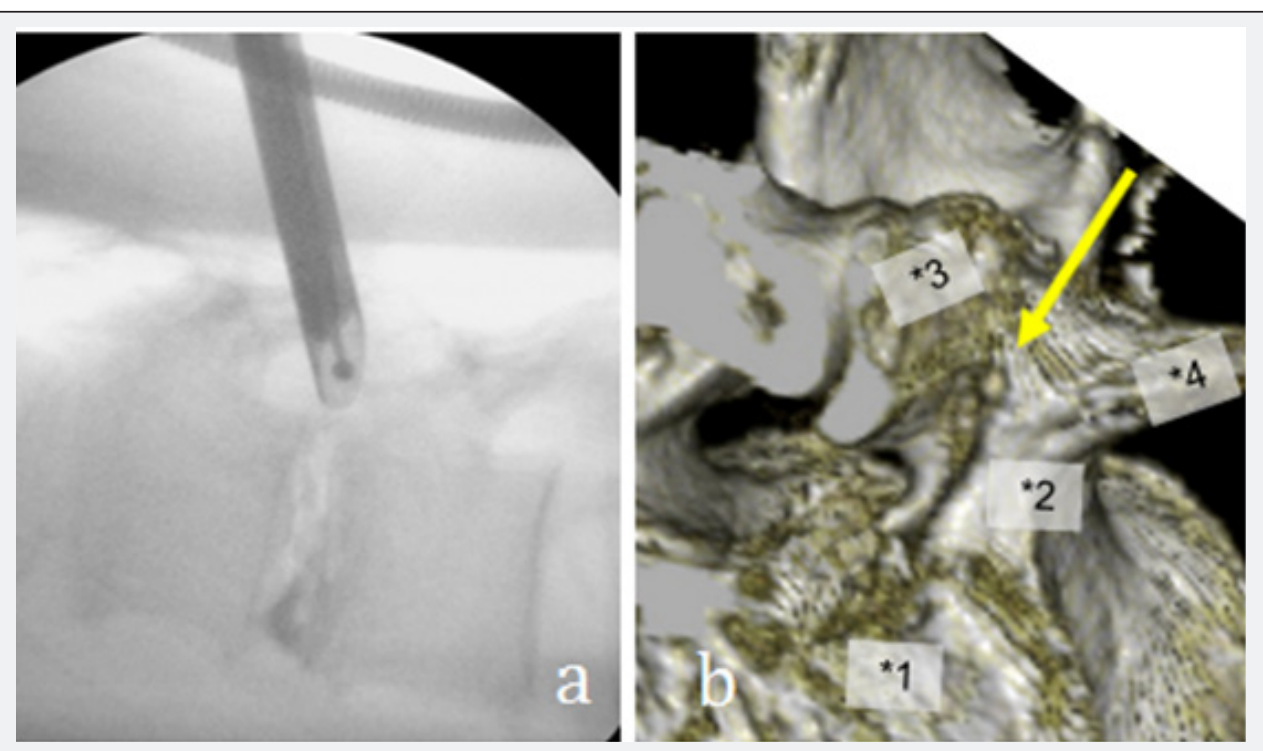

Figure 2a: When the partial pediculotomy started, we could confirm the head of the electrical high-speed drill located in the crossing part of superior facet and transverse process under lateral fluoroscopy.

Figure $\mathbf{2 b}$ : The reconstructed three-dimensional computed tomography scan clearly shows the minimal cortical bone resection of a quarter of the craniomedial part (yellow arrow) performed as partial pediculotomy. ${ }^{*} 1$ :L2 cranial endoplate, *2: L2 left pedicle, *3: superior facet, *4: transverse process. 


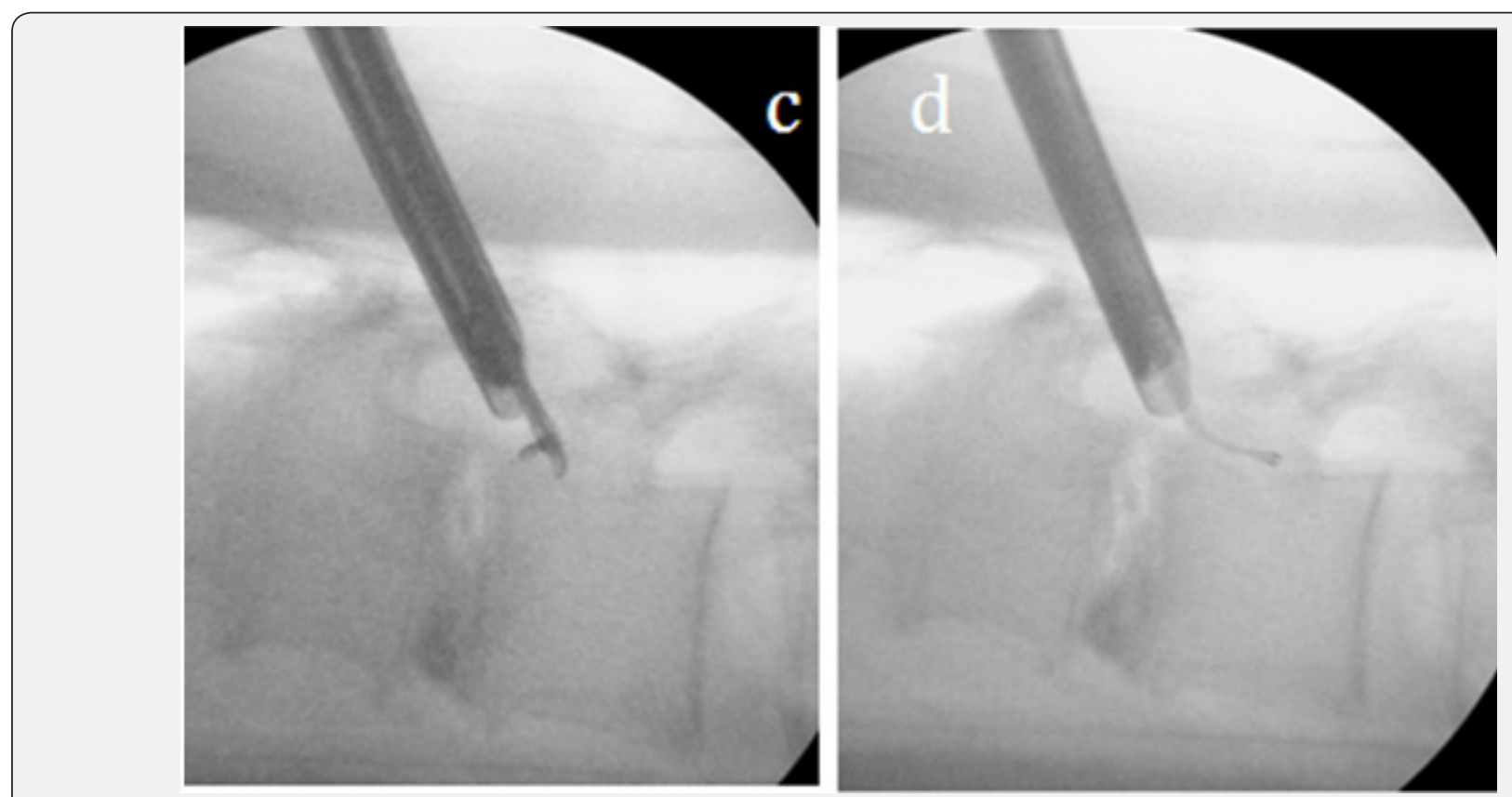

Figure 2c: After the partial pediculotomy, the migrated fragment is removed using the punch under endoscopic view with lateral fluoroscopy.Figure 2d: After the fragmentectomy, the decompressed state of the $\mathrm{L} 2$ nerve root could be confirmed using the flexible bipolar device.

PLPED with partial pediculotomy under local anesthesia was planned to decompress the left L2 nerve root. Our anesthesiologist performed deep sedation of the patient. The patient was placed in a prone position, and the puncture point under fluoroscopy was simulated prior to the calculation of data (9). An $8 \mathrm{~mm}$ skin incision was made $5 \mathrm{~cm}$ to the left of the midline. The standard PLPED procedure was started after local anesthesia. Owing to the L1-L2 foraminal severe stenosis, we selected the outsidein technique. The adverse walking technique could be used to approach the crossing point of the superior facet and transverse process (Figure 2a). Partial pediculotomy was started from this point, and a quarter of the craniomedial portion was drilled (Figure 2b) for the total fragmentectomy (Figure 2c) (10). We could decompress the L2 nerve root from the L1 endoplate level to under the midline of the L2 pedicle (Figure 2d).

The operative time was 2 hours; $100 \mathrm{ml}$ of bleeding from the L1 AEVP due to injury by the tip of the Beak-type cannula took 30 min to control. We first attempted the standard hemostatic techniques of increasing the irrigation pressure $(100$ to $110 \mathrm{~cm}$ $\mathrm{H} 2 \mathrm{O}$ for $3 \mathrm{~min}$ ) several times and compression the bleeding point with rigid dissector but did not succeed the hemostasis. We then attempted the techniques for such a vigorous bleeding situation include slow cannula rolling and bleeding point compression by a flexible bipolar device with hemostatic cotton materials. We finally achieved the hemostasis and placed a drainage tube. Little outflow stayed only in the tube, which was withdrawn the next morning without hematoma formation.

The patient did not have any dysesthesia and paresis. The time to ambulation was 2 hours, and his hospital stay was 7 days. The NRS score of his affected leg improved from 8 to 1 after 2 months. In the next morning, his wound pain NRS score was 1. The axial view of the MRI scan (Figure 1c) showed that the migrated fragment was completely removed.

\section{Discussion}

The standard treatment for higher-level lumbar disc herniation is conventional discectomy with some fusion after facetstomy (11). Nowadays, many types of minimally invasive percutaneous pedicle screw systems are available (12). Owing to the poor general condition of our patient, we selected the operative procedures suitable for local anesthesia were limited. Interlaminar PED (ILPED) with partial laminectomy $(7,8)$ and PLPED with partial pediculotomy are the best minimally techniques for patients with poor general conditions.

The major difference between ILPED and PLPED with partial pediculotomy is the direction of the operative approaches. ILPED accesses from dorsal side of vertebral laminae, thereby even combined with laminectomy the migrated fragment is still covered with neural structures. On the other hand, PLPED with partial pediculotomy can directly expose the migrated fragment covering neural structures. In other words, as the migrated fragment protects underneath neural structures, we can safely drill the inner cortical bone layer of the pedicle. Additionally, the width of spinal canal at high vertebral level (ex. L1-L2) is narrower than that at low vertebral level (ex. L5-S1) (13). Consequently ILPED at high vertebral level requires more skillful technic. Our case was affected at L1-L2 vertebral level and the migrated fragment extended lateral part of the spinal canal (Figure 1b), we therefore planned to perform the PLPED with partial pediculotomy. 
The disadvantages of PLPED under the situation of severe foraminal stenosis include the possibility of complicating the exiting nerve injury and bleeding from the AEVP. As the beaktype cannula has a wider view than the square-type cannula, we changed the square-type cannula with the beak-type cannula to complete the decompression of the L2 nerve root. When the joystick maneuver was used to observe the narrow disc space, the tip of the beak-type cannula injured the L1 AEVP. The flexible bipolar unit is the only instrument for hemostasis with the PED system. We needed $30 \mathrm{~min}$ to control $100 \mathrm{ml}$ of bleeding from the AEVP. The robotic general surgery system already has many useful instruments developed for dissection and coagulation (14). One of the urgent needs of PED surgeons is the development of a bipolar dissector for fine manipulation like under microscopic surgery.

On the basis of this case of higher-level migrated lumbar disc herniation, PLPED with partial pediculotomy is a useful procedure for patients with poor general conditions. For the appropriate development of this procedure, the PED system requires new devices to control the bleeding from the AEVP.

\section{Acknowledgment}

All the authors made a significant contribution to this case report.

\section{References}

1. Yeung AT, Yeung CA (2007) Minimally invasive techniques for the management of lumbar disc herniation. Orthop Clin North Am 38(3): 363-372.

2. Sairyo K, Egawa H, Matsuura T, Takahashi M, Higashino K, et al. (2014) State of the art: transforaminal approach for percutaneous endoscopic lumbar discectomy under local anesthesia. J Med Invest 61(3-4): 217 225 .

3. Lee S, Kim SK, Lee SH, Kim WJ, Choi WC, et al. (2007) Percutaneous endoscopic lumbar discectomy for migrated disc herniation: classification of disc migration and surgical approaches. Eur Spine ] 16(3): 431-437.

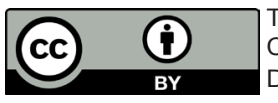

This work is licensed under Creative Commons Attribution 4.0 Licens DOI: 10.19080/JHNSS.2018.02.555596
4. Kitahama Y, Sairyo K, Dezawa A (2013) Percutaneous endoscopic transforaminal approach to decompress the lateral recess in an elderly patient with spinal canal stenosis, herniated nucleus pulposus and pulmonary comorbidities. Asian J Endosc Surg 6(2): 130-133.

5. Ying J, Huang K, Zhu M, Zhou B, Wang Y, et al. (2016) The effect and feasibility study of transforaminal percutaneous endoscopic lumbar discectomy via superior border of inferior pedicle approach for downmigrated intracanal disc herniations. Medicine (Baltimore) 95(8): e2899.

6. Li Z, Hou S, Shang W, Cao Z, Zhao H (2016) Percutaneous lumbar foraminoplasty and percutaneous endoscopic lumbar decompression for lateral recess stenosis through transforaminal approach: technique notes and 2 years follow-up. Clin Neurol Neurosurg 143: 90-94.

7. Dezawa A, Sairyo K (2011) New minimally invasive discectomy technique through the interlaminar space using a percutaneous endoscope. Asian J Endosc Surg 4(2): 94-98.

8. H Koga (2017) Improved percutaneous endoscopic translaminar approach for lumbar foraminal stenosis at L5/S1. Mini-invasive Surg 1:3-5.

9. Kitahama Y, Matsui G, Minami M, Kawaoka T, Otome K, et al. (2017) Posterolateral percutaneous endoscopic discectomy with free-running electromyography monitoring under general anesthesia. Mini-invasive Surg 1: 109-114.

10. Kitahama Y (2017) Percutaneous endoscopic lumbar foraminotomy. Spine \& Spinal Cord 30(12): 1037-1045.

11. Hoffman RM, Wheeler KJ, Deyo RA (1993). Surgery for herniated lumbar discs: a literature synthesis. J Gen Intern Med 8(9): 487-496.

12. Harris EB, Massey P, Lawrence J, Rihn J, Vaccaro A, et al. (2008) Percutaneous techniques for minimally invasive posterior lumbar fusion. Neurosurg Focus 25(2): E12.

13. Kitahama Y (2017) Posterolateral Approach. In: Supervised by Mizuno J, Nishimura Y (Eds.), Chapter 5.04, Irasuto Jutsuchu-shashin Karamanabu: Sekitsui Naisikyougeka No Zissai (Spinal endoscopic surgical procedure:Learn from the Intraoperative image). Medical Review, Tokyo, Japan, pp: 30-35.

14. Camarillo DB, Krummel TM, Salisbury JK (2004) Robotic technology in surgery: Past, present, and future. Am J Surg 188 (4A Suppl): 2S-15S.

\section{Your next submission with Juniper Publishers will reach you the below assets}

- Quality Editorial service

- Swift Peer Review

- Reprints availability

- E-prints Service

- Manuscript Podcast for convenient understanding

- Global attainment for your research

- Manuscript accessibility in different formats

( Pdf, E-pub, Full Text, Audio)

- Unceasing customer service

Track the below URL for one-step submission https://juniperpublishers.com/online-submission.php 